\title{
Management of the Axilla in the Era of Breast Cancer Heterogeneity
}

\author{
Maïlys de Meric de Bellefon ${ }^{1}$, Claire Lemanski ${ }^{1}$, Angélique Ducteil ${ }^{1}$, Pascal Fenoglietto ${ }^{1}$ \\ David Azria ${ }^{1,2,3}$ and Celine Bourgier ${ }^{1,2,3 *}$
}

${ }^{1}$ Institut Régional du Cancer de Montpellier (ICM), Montpellier, France, ${ }^{2}$ Institut de Recherche en Cancérologie de Montpellier (IRCM), INSERM U1194, Montpellier, France, ${ }^{3}$ Université de Montpellier, Montpellier, France

Systemic cancer therapies take into account breast cancer (BC) heterogeneity by targeting pathways specifically involved in some BC subtypes. On the other hand, BC intrinsic radiosensitivity is poorly understood and studied. Hence, radiotherapy personalization in $\mathrm{BC}$ is still "work in progress". In this review, we will summarize the existing data on the management of axillary lymph nodes in $\mathrm{BC}$, the impact of $\mathrm{BC}$ radiotherapy on axillary management, the indications for axillary radiotherapy, and biomarkers to predict patients' outcome (tumor control and late toxicities) after axillary irradiation.

Keywords: breast cancer, heterogeneity, radiotherapy, axilla, molecular subtypes

\section{OPEN ACCESS}

Edited by:

Pelagia G. Tsoutsou,

Center Hospitalier Universitaire Vaudois (CHUV), Switzerland

Reviewed by:

Vivek Verma,

University of Nebraska Medical

Center, United States

Olalla Santa Cruz,

Hôpital Neuchâtelois, Switzerland

*Correspondence:

Celine Bourgier

celine.bourgier@icm.unicancer.fr

Specialty section:

This article was submitted to Radiation Oncology, a section of the journal

Frontiers in Oncology

Received: 13 December 2017 Accepted: 12 March 2018 Published: 04 April 2018

Citation: de Meric de Bellefon M, Lemanski C, Ducteil A, Fenoglietto P, Azria D and

Bourgier C (2018) Management of the Axilla in the Era of Breast Cancer Heterogeneity.

Front. Oncol. 8:84 doi: 10.3389/fonc. 2018.00084

\section{INTRODUCTION}

Breast cancer (BC) is the most common cancer type in women worldwide. Treatment decisionmaking is based on the tumor histopathological features, tumor size, tumor grade, expression of hormone receptors (HRs) and HER2, lymphovascular invasion, and nodal involvement, to take into account BC morphological heterogeneity. Indeed, it has been proposed that although most tumors derive from a single mutated cell, tumor growth and aggressiveness are caused by sequential selection of more aggressive sublines that have acquired additional genetic alterations (genetic instability) (1). In 2000, BC diversity was further confirmed by the discovery that BC can be classified into different groups, according to their molecular phenotype, with different outcomes (2). Moreover, a better understanding of intratumor heterogeneity of primary BC and metastases provides clues about tumor resistance and/or genomic instability driver events, thus allowing the development of new and personalized treatments. Systemic treatment strategies are now proposed based on BC heterogeneity. Conversely, BC intrinsic radiosensitivity is poorly understood and studied, limiting the scope of personalized decision-making for locoregional treatment.

\section{METHODS}

The study objective was to identify recent literature data on axillary management and on predictive biomarkers for patients' outcome (tumor control and late toxicities) after locoregional treatment of BC. To this aim, the Medline (Pubmed) and Cochrane Library databases were searched using the following search terms: "locoregional treatment"; "breast cancer"; "axillary nodes"; "radiotherapy"; "prognostic factors"; "predictive biomarkers"; "tumor control," and "late toxicities".

\section{RESULTS}

\section{Axillary Lymph Node Dissection (ALND) and Sentinel Lymph Node Biopsy (SLNB) in Early BC}

After the publication of the results of the ACOSOG Z0011 and European Organization for Research and Treatment of Cancer (EORTC) 10981-22023 AMAROS clinical trials, ALND is mostly omitted 
for the management of early BC and replaced by $\operatorname{SLNB}(3,4)$. Some limitations could be noticed in the ACOSOG Z011 trial, particularly the absence of assurance quality, the variations regarding the irradiation protocol (15\% of patients received additional supraclavicular irradiation, prohibited by the protocol), the limited radiotherapy records (available only for $1 / 3$ of the patients who were treated with radiotherapy), and the differences between radiotherapy treatment planning and delivery (3D-conformal vs. 2D) (5). Despite these limitations, the American Society of Breast Surgeons and the National Comprehensive Cancer Network guidelines have stated that SLNB is sufficient, even in the case of nodal involvement, for patients who meet all the ACOSOG Z0011 criteria: T1-2 BC, 1 or 2 positive lymph nodes without extracapsular extension, breast-conserving surgery followed by whole breast irradiation, and patient acceptance and completion of adjuvant systemic therapy (hormonal and/or cytotoxic) (6). In this selected population, the risk of axillary relapse is about $1-3 \%$ without any impact on disease-free survival (DFS) and overall survival (OS) (7-9). Similar recommendations were formulated based on the AMAROS trial results (10).

A recent report based on data from the Surveillance, Epidemiology, and End Results population study did not find any difference in breast cancer-specific survival in patients who underwent ALND or SLNB after adjustment for tumor stage, HRs status, and tumor grade (11). The study inclusion criteria were patients with T1-2 invasive BC and 1-2 positive lymph nodes (N1 only, patients with $\mathrm{N} 0 \mathrm{i}+$ and $\mathrm{N} 1 \mathrm{mi}$ were not included). However, subgroup analyzes according to age ( $<$ or $>50$ years) and HRs status (positive or negative) showed that in the subgroup of women younger than 50 years and with a HRs-negative tumor, the $\mathrm{BC}$-specific survival rate was higher in patients who underwent ALND than in those who had SLNB [hazard ratio $(\mathrm{HR})=0.70$, $\mathrm{HR}=0.026,95 \%$ confidence interval $(\mathrm{CI})=0.51-0.96]$.

\section{Axillary Node Involvement: A Strong Prognostic Factor for BC OS}

Axillary lymph node involvement is a major prognostic factor of $\mathrm{BC}$ outcome (12): the 5-year OS is $82.8 \%$ in node-negative BC, $73 \%$ in BC with $1-3$ positive nodes, $45.7 \%$ in BC with $4-12$ positive nodes, and $28.4 \%$ in $\mathrm{BC}$ with $\geq 13$ positive nodes (13). The axillary lymph node status is a strong prognostic factor even in the case of microscopic nodal involvement with a 1.5 -fold increase in the 5-year recurrence rate in patients with $\mathrm{pN} 1 \mathrm{mi} \mathrm{BC}$ compared with patients with node-negative BC $(p=0.02)(14)$.

\section{Optimal Number of Lymph Nodes to be Removed for Accurate Staging and Survival Prediction}

When ALND is required, at least 10 lymph nodes should be removed (9). During SLNB, several sentinel and non-sentinel lymph nodes should be evaluated (1-8). As the occurrence of post-biopsy complications has been related to the number of removed lymph nodes, Ban et al. wanted to determine the optimal number of nodes to be collected for accurate prediction of the axillary lymph node status with minimal morbidity (15). By reviewing data on 328 patients with T1-2 BC who underwent
SLNB, they found that all positive sentinel lymph nodes were identified in one of the first three lymph nodes removed from patients with node-positive BC. Therefore, they recommended that no more than four sentinel lymph nodes should be removed during SLNB. When only one sentinel lymph node was removed, recurrence-free survival was significantly worse $(\mathrm{HR}=2.711$; $95 \% \mathrm{CI}=1.110-6.622 ; p=0.029)(16)$.

\section{The Role of Regional Lymph Node Irradiation (RNI)}

In addition to ALND, RNI also has contributed to improve DFS and OS in patients with node-positive BC $(17,18)$. While RNI in $\geq 4$ node-positive $\mathrm{BC}$ is the standard of care, its value in patients with 1-3 node-positive $\mathrm{BC}$ is still debated. The results of the MA.20 and EORTC 22922/10925 randomized trials showed a significant reduction in locoregional and distant relapses in patients who underwent RNI after a median follow-up of $\geq 9$ years (19, 20). The reduction in $\mathrm{BC}$ recurrence rate was independent from the tumor molecular subtype. The contribution of RNI by site (supraclavicular, internal mammary chain, and/or axilla) on the improved outcome could not be distinguished because RNI encompasses at least two lymph node sites.

Finally, for early BC, the ESTRO consensus guidelines propose an atlas for the delineation of the node clinical target volume that includes the axillary levels (level 1, its visualization is influenced by scarring after ALND or SNB; level 2, dorsal to the minor pectoral muscle; level 3, or infraclavicular region; and level 4, or supraclavicular area), the interpectoral (or Rotter) nodes, and the internal mammary nodes (21). The aim of this atlas is to provide useful and reproducible guidelines for radiation oncologists [for a full description, see Ref. (21)].

\section{Impact of Tangent Radiation Fields and Subsequent Axillary Coverage on the Locoregional Outcome}

The lowest part of the level I axillary region is usually covered by the breast tangent radiation fields, while the highest part of the level II and III axillary volumes are included in the supraclavicular irradiation field. If axillary irradiation is required, many authors consider that the usual breast tangent fields are not sufficient for optimal coverage of the level I and II axillary volumes, and an additional dedicated axillary field is needed (22).

The meta-analysis by Van Wely et al. showed that in patients with node-negative $\mathrm{BC}$, whole breast irradiation significantly reduced axillary recurrence rate (relative risk $=0.32 ; p<0.001$ ) compared with patients without radiotherapy (23). As ALND is now rarely performed in the daily practice, the addition of direct axillary irradiation could be suggested to reduce regional recurrence. In the ACOSOG Z0011 trial (patients with cT1-2 N0-1 $\mathrm{BC}$ randomly divided in the ALND and SNB arms), radiotherapy with the high tangent field method that covers the lower axilla nodes was performed in 50 and $52.6 \%$ of patients in the ALDN and SBNB arms, supraclavicular irradiation in 21.2 and $16.9 \%$ of patients, respectively, and direct axilla irradiation was not allowed (5). After a median follow-up of 9 years, no significant difference in locoregional relapse was found between arms (24). 
Following the AMAROS (4) and ACOZOG Z0011 trial results, additional ALND is now performed in fewer patients with sentinel node-positive BC. However, surgery de-escalation should be highly selective because some patients (more than $30 \%$ ) could have $\geq 4$ involved axillary nodes. Therefore, Haffty et al. suggested to perform breast irradiation with high tangent fields associated with full RNI in patients at high risk of aggressive BC (i.e., HRs-negative tumor, presence of lymphovascular invasion, multifocal disease, large tumor size, and at least three positive sentinel nodes) (25).

\section{Radiotherapy of the Axilla: for Which BC?}

Axillary management differs according to the $\mathrm{BC}$ stage. In patients with early and $\mathrm{pN} 1 \mathrm{BC}$, axillary irradiation is not recommended. The EBCTCG meta-analysis and the MA.20 and EORTC 22922/10925 trials showed a significant DFS improvement in patients with pN1 BC who received adjuvant RNI (19, 20). However, in these trials only irradiation of the level 3-4 axillary volumes and internal mammary nodes was considered.

In patients with locally advanced $\mathrm{BC}$ who undergo radical mastectomy, a meta-analysis of trials on radiotherapy of the chest wall and regional lymph nodes found that RNI and postmastectomy irradiation improve DFS and OS $(17,18)$. Axillary nodes were covered by RNI in these trials. The risk of axillary recurrence significantly increases to $21-33 \%$ in patients with histologically positive axillary nodes with limited axillary dissection and without irradiation $(7,26,27)$. In this setting, axillary node irradiation in addition to RNI is often indicated (expert agreement) (28-30).

In patients receiving neoadjuvant chemotherapy, some questions about axillary management, SLNB or ALND use, optimal SLNB timing (before or after neoadjuvant chemotherapy), and optimal irradiation volumes still need to be clearly addressed. Residual cancer cells in axillary nodes after neoadjuvant chemotherapy are a strong risk factor of locoregional relapse (31). A recent review by Pilewskie and Morrow suggested that ALND could be omitted in patients with cN0 HRs-positive and HER2negative $\mathrm{BC}$ who undergo breast-conserving surgery. However, axillary management is still unclear for patients with triple negative or HER2-overexpressing BC (32). Regarding the node target volumes, Lemanski et al. and Rivera et al. suggested that node irradiation should be proposed to patients with ypN $+\mathrm{BC}$, and axillary irradiation recommended for $\mathrm{pN} 2-3 \mathrm{BC}$, or in the case of non-optimal number of harvested lymph nodes, or massive involvement of peri-nodal adipose tissue $(33,34)$.

\section{Prognostic Tools and Biomarkers of Patients' Outcome}

The IHC4 algorithm, which includes the protein expression level of estrogen and progesterone receptors, HER2, and Ki67, has been validated for the prediction of distant recurrences in patients with BC (35). Commercial mRNA-based gene signatures are also available for the prediction of distant recurrence [Oncotype Dx ${ }^{\circledast} /$ Genomic Health; MammaPrint ${ }^{\circledast} /$ Agendia; MapQuant $\mathrm{Dx}^{\mathrm{TM}}$ (GGI)/Ipsogen/QIAGEN; and ProSigna ${ }^{\circledR} /$ NanoString; EndoPredict ${ }^{\circledR} /$ Sividon/Myriad Genetics].
For locoregional management, nomograms have been developed to accurately estimate the probability of non-sentinel lymph node involvement in patients with positive SLNB. They use prognostic factors, such as tumor size, histology, lymphovascular invasion, total number of positive lymph nodes, metastasis size, and extracapsular extension (36-38). Lymphovascular invasion is an independent prognostic factor of BC-specific survival and distant metastasis-free survival in patients with node-negative BC $(30,39)$. Lymphovascular invasion is also a significant and independent prognostic factor in patients with $\mathrm{pN} 1 \mathrm{BC}$ and tumor size $<2 \mathrm{~cm}$. More recently, a meta-analysis showed that extranodal extension of a sentinel lymph node metastasis is significantly associated with worse patients' outcome (40). The risk of recurrence and mortality is increased by twofold in the presence of extranodal extension.

Besides histological prognostic factors, some authors assessed whether specific BC molecular subtypes are associated with lymph node status. Unfortunately, no significant association was found between molecular subtypes and risk of positive nodes (41-43). Based on the hypothesis that metastatic cancer cells in axillary lymph nodes represent the most aggressive fraction of primary tumor cells, Feng et al. compared the gene expression profiles obtained by microarray analysis of matched axillary lymph node metastases and primary breast tumor with the aim of identifying predictive factors of patients' outcome (44). They found 79 genes that were differentially expressed between matched samples and that could distinguish patients at low and high risk of distant recurrences. These results need to be confirmed in a prospective study with a large cohort. More recently, Paula et al. tried to identify prognostic markers in patients with $\mathrm{pN} 0$ and $\mathrm{pN}+\mathrm{BC}$ (45) and found that the PIK3R5 gene was differentially expressed in these two groups. However, they did not assess the correlation with the patients' outcome. To date, no biomarker has been identified to stratify patients who will require ALND and axillary lymph node irradiation.

Regarding the locoregional outcome, Mamounas et al. recently reported that the Oncotype $\mathrm{DX}^{\circledR}$ recurrence score is a significant predictor of locoregional recurrence in patients with node-positive (especially, more than four nodes) and estrogen receptor-positive $\mathrm{BC}$ treated with chemo- and endocrine therapy (46). They suggested that the Oncotype $\mathrm{DX}^{\circledR}$ recurrence score could be combined with common clinicopathologic characteristics for more tailored radiotherapy.

\section{Prognostic Tools and Biomarkers of Radiotherapy Toxicity}

De-escalation from ALND to SLNB significantly decreased the risk of arm lymphedema and improved the patients' quality of life (47-49). Arm lymphedema and shoulder impairment can appear also after adjuvant breast radiotherapy, but less frequently than after $\operatorname{ALND}(50,51)$. For instance, in the AMAROS trial, the 5 -year lymphedema incidence was $11 \%$ after radiotherapy and $23 \%$ after surgery $(p<0.0001)$ (4). A study on the risk factors for lymphedema after cancer treatment in a large cohort of patients with BC showed that ALND and anthracycline-based chemotherapy significantly increased lymphedema occurrence (ALND: 
$\mathrm{HR}=2.61 ; 95 \% \mathrm{CI}=1.77-3.84$; anthracyclines: $\mathrm{HR}=1.46 ; 95 \%$ $\mathrm{CI}=1.04-2.04)$ (52). Few preclinical studies tried to identify predictive biomarkers of lymphedema risk. Newman et al. genotyped Tag single nucleotide polymorphisms for all genetic variations of genes involved in familial lymphedema and/or lymphangiogenesis in patients with $\mathrm{BC}$ who developed $(n=22)$ or not (controls, $n=98$ ) arm lymphedema after surgery (53). They found that multiple SNPs within the VEGFR2, VEGFR3, and RORC genes were associated with lymphedema $(p<0.05)$. These preliminary results need to be confirmed in a larger cohort.

To date, no predictive biomarker of lymphedema occurrence has been validated in a large cohort.

\section{CONCLUSION}

The characterization of $\mathrm{BC}$ intrinsic radiosensitivity is still in progress. In some BC population, such as patients with estrogen

\section{REFERENCES}

1. Nowell PC. The clonal evolution of tumor cell populations. Science (1976) 194:23-8. doi:10.1126/science.959840

2. Perou CM, Sørlie T, Eisen MB, van de Rijn M, Jeffrey SS, Rees CA, et al. Molecular portraits of human breast tumours. Nature (2000) 406:747-52. doi:10.1038/35021093

3. Giuliano AE, Hunt KK, Ballman KV, Beitsch PD, Whitworth PW, Blumencranz PW, et al. Axillary dissection vs no axillary dissection in women with invasive breast cancer and sentinel node metastasis: a randomized clinical trial. JAMA (2011) 305:569-75. doi:10.1001/jama.2011.90

4. Donker M, van Tienhoven G, Straver ME, Meijnen P, van de Velde CJ, Mansel RE, et al. Radiotherapy or surgery of the axilla after a positive sentinel node in breast cancer (EORTC 10981-22023 AMAROS): a randomised, multicentre, open-label, phase 3 non-inferiority trial. Lancet Oncol (2014) 15:1303-10. doi:10.1016/S1470-2045(14)70460-7

5. Jagsi R, Chadha M, Moni J, Ballman K, Laurie F, Buchholz TA, et al. Radiation field design in the ACOSOG Z0011 (alliance) trial. JClin Oncol (2014) 32:3600-6. doi:10.1200/JCO.2014.56.5838

6. TASoB S. Position Statement on Management of the Axilla in Patients With Invasive Breast Cancer. (2011). Available from: https://www.breastsurgeons. org/new_layout/about/statements/PDF_Statements/Axillary_Management. pdf

7. Dewar JA, Sarrazin D, Benhamou E, Petit JY, Benhamou S, Arriagada R, et al. Management of the axilla in conservatively treated breast cancer: 592 patients treated at institut Gustave-Roussy. Int J Radiat Oncol Biol Phys (1987) 13:475-81. doi:10.1016/0360-3016(87)90060-5

8. Louis-Sylvestre C, Clough K, Asselain B, Vilcoq JR, Salmon RJ, Campana F, et al. Axillary treatment in conservative management of operable breast cancer: dissection or radiotherapy? Results of a randomized study with 15 years of follow-up. J Clin Oncol (2004) 22:97-101. doi:10.1200/JCO.2004.12.108

9. Fisher B, Redmond C, Fisher ER, Bauer M, Wolmark N, Wickerham DL, et al. Ten-year results of a randomized clinical trial comparing radical mastectomy and total mastectomy with or without radiation. N Engl J Med (1985) 312:674-81. doi:10.1056/NEJM198503143121101

10. Mahmoud O, Haffty BG. Regional nodal management in the light of the AMAROS trial. Ann Transl Med (2015) 3:88. doi:10.3978/j.issn.23055839.2015.02.21

11. Li S, Liu F, Chen K, Rao N, Xie Y, Su F, et al. The extent of axillary surgery is associated with breast cancer-specific survival in T1-2 breast cancer patients with 1 or 2 positive lymph nodes: a SEER-population study. Medicine (2016) 95:e3254. doi:10.1097/MD.0000000000003254

12. de Boer M, van Dijck JA, Bult P, Borm GF, Tjan-Heijnen VC. Breast cancer prognosis and occult lymph node metastases, isolated tumor cells, and micrometastases. J Natl Cancer Inst (2010) 102:410-25. doi:10.1093/jnci/ djq008 receptor-positive, $\mathrm{pN}+\mathrm{BC}$, the integration of the Oncotype $\mathrm{DX}^{\circledR}$ recurrence score with common clinicopathologic characteristics could improve the prediction of the risk of locoregional recurrences and consequently allow a more tailored and comprehensive axillary management. However, axillary irradiation only concerns a small proportion of patients with BC. To date, no predictive tool or biomarker has been validated for the identification of patients who would require axillary irradiation. According to expert agreement, axillary node irradiation could be added to RNI for patients with high-risk BC after radical mastectomy and chest wall irradiation.

\section{AUTHOR CONTRIBUTIONS}

All the authors were involved in the conception/design of the work and provide approval for publication of the content more specifically. $\mathrm{MB}$ and $\mathrm{CB}$ contributed to drafting the work.

13. Fisher B, Bauer M, Wickerham DL, Redmond CK, Fisher ER, Cruz AB, et al Relation of number of positive axillary nodes to the prognosis of patients with primary breast cancer. An NSABP update. Cancer (1983) 52:1551-7.

14. Reed J, Rosman M, Verbanac KM, Mannie A, Cheng Z, Tafra L. Prognostic implications of isolated tumor cells and micrometastases in sentinel nodes of patients with invasive breast cancer: 10-year analysis of patients enrolled in the prospective East Carolina university/Anne Arundel medical center sentinel node multicenter study. J Am Coll Surg (2009) 208:333-40. doi:10.1016/ j.jamcollsurg.2008.10.036

15. Ban EJ, Lee JS, Koo JS, Park S, Kim SI, Park BW. How many sentinel lymph nodes are enough for accurate axillary staging in t1-2 breast cancer? J Breast Cancer (2011) 14:296-300. doi:10.4048/jbc.2011.14.4.296

16. Kim MK, Park HS, Kim JY, Kim S, Nam S, Park S, et al. The clinical implication of the number of lymph nodes harvested during sentinel lymph node biopsy and its effects on survival outcome in patients with node-negative breast cancer. Am J Surg (2017) 214:726-32. doi:10.1016/j.amjsurg.2016.10.019

17. EBCTCG (Early Breast Cancer Trialists' Collaborative Group), McGale P, Taylor C, Correa C, Cutter D, Duane F, et al. Effect of radiotherapy after mastectomy and axillary surgery on 10-year recurrence and 20-year breast cancer mortality: meta-analysis of individual patient data for 8135 women in 22 randomised trials. Lancet (2014) 383:2127-35. doi:10.1016/ S0140-6736(14)60488-8

18. Early Breast Cancer Trialists' Collaborative Group (EBCTCG), Darby S, McGale P, Correa C, Taylor C, Arriagada R, et al. Effect of radiotherapy after breast-conserving surgery on 10-year recurrence and 15-year breast cancer death: meta-analysis of individual patient data for 10,801 women in 17 randomised trials. Lancet (2011) 378:1707-16. doi:10.1016/S01406736(11)61629-2

19. Whelan TJ, Olivotto IA, Levine MN. Regional nodal irradiation in early-stage breast cancer. N Engl J Med (2015) 373:1878-9. doi:10.1056/NEJMoa1415340

20. Poortmans PM, Collette S, Kirkove C, Van Limbergen E, Budach V, Struikmans $\mathrm{H}$, et al. Internal mammary and medial supraclavicular irradiation in breast cancer. N Engl J Med (2015) 373:317-27. doi:10.1056/ NEJMoa1415369

21. Offersen BV, Boersma LJ, Kirkove C, Hol S, Aznar MC, Biete Sola A, et al. ESTRO consensus guideline on target volume delineation for elective radiation therapy of early stage breast cancer. Radiother Oncol (2015) 114:3-10. doi:10.1016/j.radonc.2014.11.030

22. Belkacemi Y, Allab-Pan Q, Bigorie V, Khodari W, Beaussart P, Totobenazara JL, et al. The standard tangential fields used for breast irradiation do not allow optimal coverage and dose distribution in axillary levels I-II and the sentinel node area. Ann Oncol (2013) 24:2023-8. doi:10.1093/annonc/mdt151

23. van Wely BJ, Teerenstra S, Schinagl DA, Aufenacker TJ, de Wilt JH, Strobbe LJ. Systematic review of the effect of external beam radiation therapy to the breast on axillary recurrence after negative sentinel lymph node biopsy. Br J Surg (2011) 98:326-33. doi:10.1002/bjs.7360 
24. Giuliano AE, Ballman K, McCall L, Beitsch P, Whitworth PW, Blumencranz P, et al. Locoregional recurrence after sentinel lymph node dissection with or without axillary dissection in patients with sentinel lymph node metastases: long-term follow-up from the American college of surgeons oncology group (alliance) ACOSOG Z0011 randomized trial. Ann Surg (2016) 264:413-20. doi:10.1097/SLA.0000000000001863

25. Haffty BG, Hunt KK, Harris JR, Buchholz TA. Positive sentinel nodes without axillary dissection: implications for the radiation oncologist. J Clin Oncol (2011) 29:4479-81. doi:10.1200/JCO.2011.36.1667

26. Fowble B, Solin LJ, Schultz DJ, Goodman RL. Frequency, sites of relapse, and outcome of regional node failures following conservative surgery and radiation for early breast cancer. Int J Radiat Oncol Biol Phys (1989) 17:703-10. doi:10.1016/0360-3016(89)90055-2

27. Fisher B, Wolmark N, Bauer M, Redmond C, Gebhardt M. The accuracy of clinical nodal staging and of limited axillary dissection as a determinant of histologic nodal status in carcinoma of the breast. Surg Gynecol Obstet (1981) 152:765-72.

28. Gradishar WJ, Anderson BO, Balassanian R, Blair SL, Burstein HJ, Cyr A, et al. NCCN guidelines insights: breast cancer, version 1.2017. J Natl Compr Canc Netw (2017) 15:433-51. doi:10.6004/jnccn.2017.0044

29. Belkacémi Y, Fourquet A, Cutuli B, Bourgier C, Hery M, Ganem G, et al. Radiotherapy for invasive breast cancer: guidelines for clinical practice from the French expert review board of Nice/Saint-Paul de Vence. Crit Rev Oncol Hematol (2011) 79:91-102. doi:10.1016/j.critrevonc.2010.06.002

30. Coates AS, Winer EP, Goldhirsch A, Gelber RD, Gnant M, Piccart-Gebhart $\mathrm{M}$, et al. Tailoring therapies - improving the management of early breast cancer: St Gallen International expert consensus on the primary therapy of early breast cancer 2015. Ann Oncol (2015) 26:1533-46. doi:10.1093/annonc/ mdv221

31. Mamounas EP, Anderson SJ, Dignam JJ, Bear HD, Julian TB, Geyer CE Jr, et al. Predictors of locoregional recurrence after neoadjuvant chemotherapy: results from combined analysis of National surgical adjuvant breast and bowel project B-18 and B-27. J Clin Oncol (2012) 30:3960-6. doi:10.1200/ JCO.2011.40.8369

32. Pilewskie M, Morrow M. Axillary nodal management following neoadjuvant chemotherapy: a review. JAMA Oncol (2017) 3:549-55. doi:10.1001/ jamaoncol.2016.4163

33. Lemanski C, Druet X, Riou O, Ducteil A, Azria D, Bourgier C. [Which node area should be irradiated after neoadjuvant chemotherapy in breast cancer?]. Cancer Radiother (2015) 19:271-5. doi:10.1016/j.canrad.2015.02.011

34. Rivera S, Louvel G, Rivin Del Campo E, Boros A, Oueslati H, Deutsch E. [Prophylactic axillary radiotherapy for breast cancer]. Cancer Radiother (2015) 19:253-60. doi:10.1016/j.canrad.2015.05.001

35. Bartlett JM, Christiansen J, Gustavson M, Rimm DL, Piper T, van de Velde CJ, et al. Validation of the IHC4 breast cancer prognostic algorithm using multiple approaches on the multinational TEAM clinical trial. Arch Pathol Lab Med (2016) 140:66-74. doi:10.5858/arpa.2014-0599-OA

36. Mittendorf EA, Hunt KK, Boughey JC, Bassett R, Degnim AC, Harrell R, et al. Incorporation of sentinel lymph node metastasis size into a nomogram predicting nonsentinel lymph node involvement in breast cancer patients with a positive sentinel lymph node. Ann Surg (2012) 255:109-15. doi:10.1097/ SLA.0b013e318238f461

37. Van Zee KJ, Manasseh DM, Bevilacqua JL, Boolbol SK, Fey JV, Tan LK, et al. A nomogram for predicting the likelihood of additional nodal metastases in breast cancer patients with a positive sentinel node biopsy. Ann Surg Oncol (2003) 10:1140-51. doi:10.1245/ASO.2003.03.015

38. Bi X, Wang Y, Li M, Chen P, Zhou Z, Liu Y, et al. Validation of the memorial sloan kettering cancer center nomogram for predicting non-sentinel lymph node metastasis in sentinel lymph node-positive breast-cancer patients. Onco Targets Ther (2015) 8:487-93. doi:10.2147/OTT.S78903

39. Rakha EA, Martin S, Lee AH, Morgan D, Pharoah PD, Hodi Z, et al. The prognostic significance of lymphovascular invasion in invasive breast carcinoma. Cancer (2012) 118:3670-80. doi:10.1002/cncr.26711

40. Nottegar A, Veronese N, Senthil M, Roumen RM, Stubbs B, Choi AH, et al. Extra-nodal extension of sentinel lymph node metastasis is a marker of poor prognosis in breast cancer patients: a systematic review and an exploratory meta-analysis. Eur J Surg Oncol (2016) 42:919-25. doi:10.1016/ j.ejso.2016.02.259

41. Liu YH, Wang OC, Chen ED, Cai YF, Pan CM, Yang F, et al. Unexpected features of breast cancer subtype. World J Surg Oncol (2015) 13:249. doi:10.1186/s12957-015-0665-8

42. Shriver CD, Hueman MT, Ellsworth RE. Molecular signatures of lymph node status by intrinsic subtype: gene expression analysis of primary breast tumors from patients with and without metastatic lymph nodes. J Exp Clin Cancer Res (2014) 33:116. doi:10.1186/s13046-014-0116-3

43. Jones T, Neboori H, Wu H, Yang Q, Haffty BG, Evans S, et al. Are breast cancer subtypes prognostic for nodal involvement and associated with clinicopathologic features at presentation in early-stage breast cancer? Ann Surg Oncol (2013) 20:2866-72. doi:10.1245/s10434-013-2994-6

44. Feng Y, Sun B, Li X, Zhang L, Niu Y, Xiao C, et al. Differentially expressed genes between primary cancer and paired lymph node metastases predict clinical outcome of node-positive breast cancer patients. Breast Cancer Res Treat (2007) 103:319-29. doi:10.1007/s10549-006-9385-7

45. Paula LM, De Moraes LH, Do Canto AL, Dos Santos L, Martin AA, Rogatto SR, et al. Analysis of molecular markers as predictive factors of lymph node involvement in breast carcinoma. Oncol Lett (2017) 13:488-96. doi:10.3892/ ol.2016.5438

46. Mamounas EP, Liu Q, Paik S, Baehner FL, Tang G, Jeong JH, et al. 21-Gene recurrence score and locoregional recurrence in node-positive/ER-positive breast cancer treated with chemo-endocrine therapy. J Natl Cancer Inst (2017) 109(4):djw259. doi:10.1093/jnci/djw259

47. Veronesi U, Paganelli G, Viale G, Luini A, Zurrida S, Galimberti V, et al. A randomized comparison of sentinel-node biopsy with routine axillary dissection in breast cancer. N Engl J Med (2003) 349:546-53. doi:10.1056/ NEJMoa012782

48. Fleissig A, Fallowfield LJ, Langridge CI, Johnson L, Newcombe RG, Dixon JM, et al. Post-operative arm morbidity and quality of life. Results of the ALMANAC randomised trial comparing sentinel node biopsy with standard axillary treatment in the management of patients with early breast cancer. Breast Cancer Res Treat (2006) 95:279-93. doi:10.1007/s10549-005-9025-7

49. Land SR, Kopec JA, Julian TB, Brown AM, Anderson SJ, Krag DN, et al. Patient-reported outcomes in sentinel node-negative adjuvant breast cancer patients receiving sentinel-node biopsy or axillary dissection: National surgical adjuvant breast and bowel project phase III protocol B-32. J Clin Oncol (2010) 28:3929-36. doi:10.1200/JCO.2010.28.2491

50. Deutsch M, Land S, Begovic M, Sharif S. The incidence of arm edema in women with breast cancer randomized on the National surgical adjuvant breast and bowel project study B-04 to radical mastectomy versus total mastectomy and radiotherapy versus total mastectomy alone. Int J Radiat Oncol Biol Phys (2008) 70:1020-4. doi:10.1016/j.ijrobp.2007.07.2376

51. Lee TS, Kilbreath SL, Refshauge KM, Herbert RD, Beith JM. Prognosis of the upper limb following surgery and radiation for breast cancer. Breast Cancer Res Treat (2008) 110:19-37. doi:10.1186/bcr1865

52. Norman SA, Localio AR, Potashnik SL, Simoes Torpey HA, Kallan MJ, Weber $\mathrm{AL}$, et al. Lymphedema in breast cancer survivors: incidence, degree, time course, treatment, and symptoms. J Clin Oncol (2009) 27:390-7. doi:10.1200/ JCO.2008.17.9291

53. Newman B, Lose F, Kedda MA, Francois M, Ferguson K, Janda M, et al. Possible genetic predisposition to lymphedema after breast cancer. Lymphat Res Biol (2012) 10:2-13. doi:10.1089/lrb.2011.0024

Conflict of Interest Statement: The authors declare that the research was conducted in the absence of any commercial or financial relationships that could be construed as a potential conflict of interest.

Copyright (c) 2018 de Meric de Bellefon, Lemanski, Ducteil, Fenoglietto, Azria and Bourgier. This is an open-access article distributed under the terms of the Creative Commons Attribution License (CC BY). The use, distribution or reproduction in other forums is permitted, provided the original author(s) and the copyright owner are credited and that the original publication in this journal is cited, in accordance with accepted academic practice. No use, distribution or reproduction is permitted which does not comply with these terms. 